\title{
Experimental assessment of new insulation coatings for lean burn spark-ignited engines
}

\author{
Jérôme Chérel ${ }^{1}$, Jean-Marc Zaccardi ${ }^{2,}$, Bernard Bouteiller $^{3}$, and Alain Allimant ${ }^{3}$ \\ ${ }^{1}$ IFP Energies nouvelles, 1 et 4 avenue de Bois-Préau, 92852 Rueil-Malmaison, France; Institut Carnot IFPEN Transports Energie \\ ${ }^{2}$ IFP Energies nouvelles, Rond-Point de l'Échangeur de Solaize, BP 3, 69360 Solaize, France; Institut Carnot IFPEN Transports \\ Energie \\ ${ }^{3}$ Saint-Gobain Research Provence, 550 Avenue Alphonse Jauffret, 84306 Cavaillon, France
}

Received: 14 June 2019 / Accepted: 24 January 2020

\begin{abstract}
Clean and highly efficient internal combustion engines will still be necessary in the future to meet the ambitious $\mathrm{CO}_{2}$ emissions reduction targets set for light-duty vehicles. The maximal efficiency of stoichiometric Spark-Ignited (SI) gasoline engines has been steadily increasing in recent years but remains limited by the important relative share of cooling losses. Low heat rejection engines using ceramic barrier coatings have been presented in the past but smart insulation coatings are gaining a renewed interest as a more promising way to further increase the engine maximal thermal efficiency. This article is highlighting some important effects of smart insulation coatings developed for lean-burn spark-ignited gasoline engines. Five different coatings with low heat conductivity and capacity are applied on aluminum engine parts with the atmospheric plasma spray technique and are tested with two different engines. The laser induced phosphorescence technique is firstly used in an optical single cylinder engine to quantify the thermal performance of these coatings in terms of temperature swing during combustion. A maximal increase in the piston surface temperature of around $100{ }^{\circ} \mathrm{C}$ is measured at low load, confirming thus the expected impact of the low heat conductivity and capacity, and suggesting thus a positive impact on fuel consumption. Thanks to the tests performed with a similar metal single cylinder engine, it is shown that the unburned hydrocarbon emissions can significantly increase by up to $25 \%$ if the open porosity on top of the coating is not properly sealed, while the surface roughness has no impact on these emissions. When applied on both the piston and the cylinder head, the optimized coating displays some distinct effects on the maximal heat release rate and NOx emissions, indicating that the thermal environment inside the combustion chamber is modified during combustion. Thanks to the temperature swing between cold and hot engine phases the volumetric efficiency can also be kept constant. However, no increase in efficiency can be measured with this optimized coating which suggests that the heat balance is not affected only by the reduction in the temperature differential between the walls and the gas.
\end{abstract}

\section{Nomenclature}

APS

CAD

EVC

IMEP

IVO

LIP

SEM

SiRPA

TDC

YSZ
Atmospheric Plasma Spraying

Crank Angle Degree

Exhaust Valve Closing

Indicated Mean Effective Pressure

Intake Valve Opening

Laser Induced Phosphorescence

Scanning Electron Microscope

Silica Reinforced Porous Anodized Aluminum

Top Dead Center

Yttria-Stabilized Zirconia $\lambda$

uHC Unburned Hydrocarbon Emissions

$\mathrm{R}_{\mathrm{a}} \quad$ Roughness average (arithmetic average of the absolute values of the profile heights over the evaluation length)

\section{Introduction}

Reduction of greenhouse gas emissions of transport sector is a significant but necessary challenge to be overcome in order to limit the global warming. Consequently, ambitious $\mathrm{CO}_{2}$ emissions reduction targets have been set for lightduty vehicles all around the world and although the majority of future powertrain architectures will be electrified,

\footnotetext{
* Corresponding author: j-marc.zaccardi@ifpen.fr
} 
it will be essential to also develop clean and highly efficient internal combustion engines. It is difficult to reliably and precisely forecast what the automotive market will look like in 2030 but the current sales scenarios show a strong preference for gasoline engines to the detriment of Diesel powertrains.

The maximal efficiency of stoichiometric Spark-Ignited (SI) gasoline engines has been steadily increasing in recent years but remains, however, limited by the important relative share of cooling losses. These losses could be reduced by diluting the air-fuel mixture by means of large amounts of extra air or exhaust gas recirculation, or also by the use of insulation coatings. Some ceramic insulation coatings for internal combustion engines had already been developed and tested more than 30 years ago but they have recently gained renewed interest when a "smart" insulation coating was developed and put on the market by Toyota.

An extensive literature is now available on this topic since thermal barrier coatings have first been developed and tested on low heat rejection Diesel engines in the 1980s [1] and some minor attempts were also made at that same period with SI engines [2]. The main objective of these thick ceramic insulation coatings was originally to increase the surface temperature in order to decrease the temperature difference between the combustion chamber walls and the hot gases during combustion, and thus to lower the convective heat transfer flux. However, the increased wall temperature during the intake stroke would also result in lower volumetric efficiency and in increased NOx emissions for Diesel engines because of the increased intake air temperature. In the case of SI engines, it can also be assumed that the knock and pre-ignition resistance would be downgraded if the air-fuel mixture is heated up during the intake stroke but it is difficult to identify any relevant literature on this topic because of the tremendous evolution of the gasoline fuel properties and SI engine technologies these last years.

A very large part of the recent literature still concerns Diesel engines developed either for heavy-duty [3-5] or light-duty applications [6-8]. Several recent nationally funded projects are also considering compression ignition engines using steel or aluminum pistons $[9,10]$.

Yttria Stabilized Zirconia (YSZ) which was one of the most applied Thermal Barrier Coating in the 1980s was considered once again more recently by Binder et al. [3] for a fundamental study combining direct flame visualization and piston surface temperature measurements with an heavy-duty single cylinder engine using a steel base piston. Uchida and Osada [4] also reported the results of an extensive study using Zirconia based insulation coatings applied on the steel piston of an heavy-duty single cylinder engine. Based upon thermodynamic analyses and direct observations of flame impingement, it is shown first that much lower heat capacity and conductivity than Zirconia are required to achieve a significant temperature swing, and also that the thermal boundary layer thickness can be lowered because of the coating, resulting thus in a higher heat transfer coefficient. The impact of coating location on cooling losses and volumetric efficiency was recently reported by Uchihara et al. [5]. Thanks to both simulations and engine tests, the location of a Zirconia based coating was optimized on an aluminum piston and it was shown that a better trade-off between increased efficiency and increased smoke emissions could be expected with an only partially insulated piston.

For passenger cars, a theoretical study was already reported in 2011 by Fujimoto et al. [6]. Simulation results showed then that very high engine efficiencies could be expected by combining high compression ratios and coatings with extremely low heat capacity and heat conductivity (ideally around or lower than $1 / 100$ of those of aluminum). In line with these results, Caputo et al. [7] have then compared the performance of YSZ to those of an anodized aluminum based coating featuring lower thermal conductivity and heat capacity. Simulations performed for a 1.6 L Euro 6 Diesel engine showed that BSFC reductions up to $0.8 \%$ could be expected with anodized aluminum while no benefit was observed with the YSZ based coating. An exhaustive study was also recently reported by Kaudewitz et al. [8] based upon a thorough research campaign considering more than 30 different coatings. Base performance of insulation coatings have been first quantified thanks to a complete 3D CFD process and key phenomena regarding the coating roughness have also been numerically assessed. The performance of promising coatings obtained by Plasma Electrolytic Oxidation have then been evaluated experimentally with a three cylinders 1.5 L Diesel engine. Unfortunately, none of the tested coatings could show benefits in specific fuel consumption over the entire engine map despite their high porosities and their low thermal conductivities and heat capacities.

Steel pistons coated by Atmospheric Plasma Spraying (APS), High Velocity Suspension Flame Spraying and Suspension Plasma Spraying have also been considered for example in [9], while a hollow nickel-alloy microsphere based coating is considered [10] in order to achieve an extremely high porosity of $90 \%$.

Facing these contrasting and sometimes contradictory results, the challenge is more than ever to develop new coatings enabling the walls temperature to follow as quickly as possible the gas temperature variation during the engine cycle, namely "smart" or "temperature-following" insulation coatings. Contrary to thick and dense ceramic coatings previously developed, thin and porous layers are targeted for these smart coatings so that the coated walls temperature can follow the average gas temperature and thereby efficiently reduce the convective heat exchanges. In this context, Toyota introduced a few years ago a Silica Reinforced Porous Anodized Aluminum (SiRPA) coating [11] claiming that gains in efficiency can be achieved without any drawback with respect to pollutant emissions or volumetric efficiency. To achieve this performance, it is necessary on the one hand to minimize the thermal conductivity and heat capacity, and on the other hand to optimize the smart coating thickness in order to reduce the heat flux from the hot gas to the walls during combustion (the thicker the better), while controlling the flux from the walls to the gas during the engine cold phases (the 
thinner the better). This new SiRPA technology has been put on the market on some Diesel engines but to the author's knowledge the application of this SiRPA coating to the combustion chamber walls of a SI engine has been reported for the first time only very recently [12]. A qualitative comparison between Diesel and SI engines is shown by Yamashita et al. regarding the influence of engine load on the potential insulation effect of the SiRPA coating but neither gains in efficiency nor interactions with knocking combustion are mentioned.

The objective of this article is to highlight some effects of smart insulation coatings applied to SI engines running in lean conditions. These engines could offer a significant advantage in terms of fuel consumption compared to stoichiometric engines but with technical definitions and combustion modes that are far different from those of previously tested coated engines. Sections 2 and 3 are introducing first the smart insulation coatings considered in these works and the experimental apparatus used to quantify the thermal and thermodynamic performance obtained with these coatings. Experimental results obtained with two single cylinder engines are then presented in Section 4. The last Section 5 finally summarizes the main conclusions and the additional perspectives to further improve these coatings.

\section{Smart insulation coatings}

Smart insulation coatings have been developed in this study in order to maximize the surface temperature swing during combustion while keeping an average surface temperature close to the reference uncoated aluminum case during the intake stroke. In accordance with the already available literature [11], the thermal conductivity and heat capacity should be minimized and the coating thickness should not be greater than around $100 \mu \mathrm{m}$, which means at least two to three times thinner than previously developed ceramic thermal barrier coatings. The optimization of thermal properties relies on the selected materials but also on the internal structure (heat flow path way, contact resistance, pore thermal resistance, etc.). Therefore, in addition to the thermal performance, the thermomechanical resistance should be taken into account as well as the adhesion strength between the coating and the aluminum substrate, and among the different layers within the coating. In order to comply with these different constraints, several multilayers coatings have been designed and applied by APS (see Tab. 1, the materials selection and APS process optimization have been recently introduced during the last International Thermal Spray Conference and Exposition [13]).

For the uncoated reference configuration, the aluminum substrate material has a thermal conductivity of about $142 \mathrm{~W} \mathrm{~m} \mathrm{~m}^{-1} \mathrm{~K}^{-1}$ and heat capacity of about $2376 \mathrm{~kJ} \mathrm{~m}^{-3} \mathrm{~K}^{-1}$. The wall surface roughness is below $1 \mu \mathrm{m}$, and the porosity is zero. Coatings $\# \mathrm{~A}, \# \mathrm{C}, \# \mathrm{D}$, and $\# \mathrm{E}$ have been tested with an optical single cylinder engine, while coatings $\# \mathrm{~A}, \# \mathrm{~B}, \# \mathrm{C}$, and $\# \mathrm{E}$ have been tested with a metal single cylinder engine.

\section{Experimental setup}

\subsection{Metal single cylinder engine}

Experimental investigations performed with the metal Single Cylinder Engine (SCE) aims at quantifying the impacts of smart insulation coatings on combustion, especially on efficiency and cooling losses. The test campaign was performed with a direct injection engine using a high compression ratio and specific intake ports promoting a high tumble motion and enabling thus to extend the dilution limits with air. Table 2 summarizes the main characteristics of this engine.

As for the fuel a commercial E10 gasoline was used. Gasoline was directly injected (central position) with a constant injection pressure of 200 bar. The gasoline fuel consumption was measured with a Coriolis flowmeter (Emerson Elite series CMFS010). This device was used in addition to the standard AVL fuel mass flow meter in order to improve the accuracy of fuel consumption measurement. The measurement uncertainty claimed for this Coriolis flowmeter is $0.1 \%$. However, the overall accuracy of the fuel consumption measurement at the test bed does not only depend on the accuracy of the flowmeter, but also on the complete test bed environment (for example on the $\lambda$ regulation) and also on the combustion stability. For this test campaign, the overall accuracy has thus been estimated by performing repeatability tests ( $\lambda$ variations) with the uncoated aluminum reference configuration and by calculating the average deviations between these repeatability tests. It has thus been shown that the average deviation is in the range of $0.2-0.3 \%$ with a peak value at $0.6 \%$.

Gasoline injection and ignition timings were controlled with an in-house control module. Oil, coolant, and fuel were supplied by electrically driven pumps. Oil and coolant temperatures were maintained at $90{ }^{\circ} \mathrm{C} \pm 2{ }^{\circ} \mathrm{C}$ and tests were performed only in steady-state conditions. The pressurized intake air was provided by an external compressor through a sonic flow meter and a flap was used in the exhaust line to simulate the backpressure of a turbine. Intake, exhaust, and in-cylinder pressures were measured with conventional sensors (water-cooled at the exhaust and inside the cylinder) and the measurements were postprocessed with an in-house software to calculate the combustion characteristics (heat release rate and mass fraction burned). The concentration of the main pollutants (uHC, CO, and NOx) were measured with conventional gas analyzers. Smoke emissions were measured with an AVL 415S smoke meter and the exhaust line was completed with a $\lambda$ sensor.

Investigations were performed for several operating points and for each of them the dilution rate by air has been varied in order to quantify the impacts of smart insulation coatings on engine performance with stoichiometric and lean mixtures. Only results obtained at $3000 \mathrm{rpm}$ and 7 bar IMEP are shown in this article. In these conditions, knock-free operation at optimal combustion timing is possible. For this operating point, the engine is operated in a naturally aspirated mode. Intake pressure and fuel flow rate are simultaneously controlled to adjust the dilution rate $(\lambda)$, 
Table 1. Measured insulation coating properties at $300{ }^{\circ} \mathrm{C}$.

\begin{tabular}{|c|c|c|c|c|c|}
\hline Name & $\# \mathrm{~A}$ & $\# \mathrm{~B}$ & $\# \mathrm{C}$ & $\# \mathrm{D}$ & $\# \mathrm{E}$ \\
\hline Nature & $\begin{array}{l}\text { Single layer } \\
\text { - Quasi crystal/ } \\
\text { ceramic } \\
\text { oxide composite }\end{array}$ & $\begin{array}{l}\text { Double layer } \\
\text { - Quasi crystal/ } \\
\text { ceramic } \\
\text { oxide composite } \\
\text { - Sealing silica layer } \\
\text { on top }\end{array}$ & $\begin{array}{l}\text { Single layer } \\
\text { - Polymer/ } \\
\text { ceramic } \\
\text { oxide composite }\end{array}$ & $\begin{array}{l}\text { Double layer } \\
\text { - Polymer/ } \\
\text { ceramic } \\
\text { exide composite } \\
\text { - Dense ceramic } \\
\text { oxide on top }\end{array}$ & $\begin{array}{l}\text { Triple layer } \\
\text { - Quasi crystal/ } \\
\text { ceramic } \\
\text { oxide composite } \\
\text { - Dense ceramic } \\
\text { oxide layer } \\
\text { - Sealing silica layer } \\
\text { on top }\end{array}$ \\
\hline $\begin{array}{l}\text { Thickness on parts } \\
\text { for metal engine }[\mu \mathrm{m}]\end{array}$ & Piston: $126 \pm 7$ & Piston: $160 \pm$ NA & Piston: $104 \pm 7$ & NA & $\begin{array}{l}\text { Piston: } 207 \pm 20 \\
\text { Cyl. head: } 154 \pm 20\end{array}$ \\
\hline $\begin{array}{l}\text { Thickness on parts for } \\
\text { optical engine }[\mu \mathrm{m}]\end{array}$ & Piston: $158 \pm 8$ & $\mathrm{NA}$ & Piston: $126 \pm 10$ & $\begin{array}{l}\text { Piston: } \\
130 \pm \mathrm{NA}\end{array}$ & Piston: $133 \pm 8$ \\
\hline Roughness $R_{a}[\mu \mathrm{m}]$ & 8 & 1 & 10 & 5 & 2 \\
\hline $\begin{array}{l}\text { Conductivity } \\
{\left[\mathrm{W} \mathrm{m} \mathrm{m}^{-1} \mathrm{~K}^{-1}\right]}\end{array}$ & 0.79 & 0.88 & 0.38 & 0.46 & 0.85 \\
\hline $\begin{array}{l}\text { Heat capacity } \\
{\left[\mathrm{kJ} \mathrm{m}^{-3} \mathrm{~K}^{-1}\right]}\end{array}$ & 1600 & 2500 & 1200 & 1700 & 2600 \\
\hline Density [-] & 4.2 & 4.1 & 1.8 & 2.3 & 4.2 \\
\hline
\end{tabular}

NA, not available.

Table 2. Metal single cylinder engine main characteristics.

\begin{tabular}{lcc}
\hline Cylinder displacement & {$\left[\mathrm{cm}^{3}\right]$} & 410.9 \\
Valves & {$[-]$} & 4 \\
Stroke & {$[\mathrm{mm}]$} & 93.0 \\
Bore & {$[\mathrm{mm}]$} & 75.0 \\
Compression ratio & {$[-]$} & $14: 1$ \\
$\begin{array}{l}\text { Tumble level } \\
\text { Intake valve lift }\end{array}$ & {$[-]$} & 2.4 \\
duration & {$[\mathrm{CAD}]$} & 140 \\
$\begin{array}{l}\text { EVC/IVO at } \\
1 \text { mm lift }\end{array}$ & {$[\mathrm{CAD}$ aTDC] } & $-10 / 10$ \\
E10 injection mode & {$[-]$} & $\begin{array}{c}\text { Central direct } \\
\text { injection }\end{array}$ \\
& & \\
\hline
\end{tabular}

and IMEP. It can also be noted that all the results presented in Section 4.2 were obtained in stable conditions with coefficient of variation of IMEP lower than $1.5 \%$, and that the compression ratio has been adapted for each tested configuration based upon the measured coatings thicknesses. With a coating thickness of $100 \mu \mathrm{m}$ on the piston surface, the compression ratio would be increased up to 14.2:1 ( +0.2 compared to the baseline). This increase might seem limited but it could theoretically have the same impact on fuel consumption reduction as the expected impact for the coatings.

\subsection{Optical single cylinder engine}

An optical engine was used in parallel to the testing phase performed with the metal single cylinder engine. This optical engine has very similar characteristics as the metal engine as shown in Table 3, the main difference being the use of port fuel injection and not direct injection. In the case of direct injection, the insulation coating might have an effect on spray/walls interactions, and consequently on mixture preparation and flame propagation. The tests reported here with the optical engine and port fuel injection aim at quantifying only the thermal performance of insulation coatings without any interference between liquid fuel spray and the walls. New pistons have been specifically designed and coated to perform these tests with the same compression ratio as for the metal engine. The test bed environment was similar to that used for the metal engine and the effects of several coatings have been investigated for two operating points at $2000 \mathrm{rpm}, 4$ bar IMEP and 1500 rpm, 6 bar IMEP.

The Laser Induced Phosphorescence (LIP) technique was applied in this optical engine to measure the piston 
Table 3. Optical single cylinder engine main characteristics.

\begin{tabular}{lcc}
\hline Cylinder displacement & {$\left[\mathrm{cm}^{3}\right]$} & 399.5 \\
Valves & {$[-]$} & 4 \\
Stroke & {$[\mathrm{mm}]$} & 85.8 \\
Bore & {$[\mathrm{mm}]$} & 77.0 \\
Compression ratio & {$[-]$} & $14: 1$ \\
Tumble level & {$[-]$} & 1.5 \\
Intake valve lift duration & {$[\mathrm{CAD}]$} & 190 \\
EVC/IVO at 1 mm lift & {$[\mathrm{CAD}$ aTDC] } & $-10 / 10$ \\
E10 injection mode & {$[-]$} & Port injection \\
\hline
\end{tabular}

surface temperature during combustion and to quantify the temperature swing obtained with various coatings. The surface temperature of uncoated pistons could be measured with other techniques than the LIP, with thermocouples or heat flux sensors for example. However, none of these techniques could be used with smart insulation coatings of around $100 \mu \mathrm{m}$ since they would require to machine the piston surface. LIP offers here the great advantage of being non-intrusive. This technique exploits the temperaturedependent luminescent properties of rare-earth or transition metal doped ceramic phosphors $[14,15]$. Different phosphors feature decay lifetimes sufficiently short for crank-angle resolved measurements and can be used depending on the targeted temperature range. Here, a phosphorous coating (Lanthanum Oxysulphide doped with Europium $\mathrm{La}_{2} \mathrm{O}_{2} \mathrm{~S}: \mathrm{Eu}$ ) is mixed with an hydroxypropyl cellulose binder and applied on the piston surface with an airbrush. Then, the phosphorescence is generated by a UV laser beam excitation using the third harmonic of a pulsed Nd:YAG laser at $355 \mathrm{~nm}$. The phosphorescence emission is collected by six quartz optical fibers, and then filtered before the photomultiplier which is connected to a fast oscilloscope recording the decays of light emission. The surface temperature can finally be calculated based upon the emission lifetime. The complete LIP measurement setup including the calibration process is the same as that used in [14] and is also illustrated in Figure 1.

The optical engine used in this study offers an almost perfectly vertical endoscopic access (inclination $7^{\circ}$ ) located just above the center of the piston. Thanks to this vertical setup, the temperature can be measured at the same location whatever the piston position during the engine cycle. On the other hand, the main drawback is that the surface temperature can only be known at the center of the piston, and not on the outer edge. Figure 2 shows the piston top view and the specific area where the phosphorous coating was applied is highlighted with the hatched red surface (the thermal insulation coating being applied on the whole top piston surface). The central piston cavity and the tilted squish areas that can be observed in Figure 2 are designed to achieve a high compression ratio similar to that of the metal single cylinder engine. This type of piston cavity is usually designed to enhance the tumble motion close to top dead center but it is also the opportunity here to apply the phosphorous coating at the center of the combustion chamber at the vertical of the endoscopic access.

Due to the different laser and engine operating frequencies, the surface temperature is measured three times every five engine cycles for each crankshaft angular position. The temperature variation over the whole engine cycle is then obtained by collecting all these measurements. In this article, only the mean temperatures at each crank angle degree are shown.

The application of LIP technique to coated pistons is more complex than for usual machined aluminum pistons because of the surface roughness and open porosity of coated pistons. It is very important to control the thickness of the phosphorous coating to be sure that the measured temperature is well representative of the wall temperature. A low thickness of the order of $10-20 \mu \mathrm{m}$ is thus necessary to observe fast transient phenomena $[15,16]$. Consequently, the roughness of smart insulation coatings should be well controlled before proceeding with the tests. Otherwise, the phosphorous coating could fill the voids available on the surface of the smart coating, without covering the entire surface with a uniform thickness. The phosphorous coating could also infiltrate the open porosity on top of the smart coating. In that case, it would not be longer possible to precisely control the thickness of this phosphorescent coating on the surface.

Scanning Electron Microscope (SEM) analyses have been performed to measure the thickness of the phosphorescent coating on various samples with or without any smart insulation coating. In all cases, the phosphorous coating has been applied exactly in the same way as for the pistons used for engine tests. These SEM measurements clearly show that the phosphorous coating thickness is homogeneous on top of the samples surfaces and controlled well below $20 \mu \mathrm{m}$. Figure 3 shows that the phosphorous coating is homogeneously applied on top of the smart coating, and also that the phosphorous coating thickness equals the size of the white Lanthanum crystals below $10 \mu \mathrm{m}$ (EnergyDispersive X-ray Spectroscopy was used to analyze the chemical composition of these white crystals and confirmed that they were made of $\mathrm{La}, \mathrm{S}, \mathrm{Eu}$, and $\mathrm{O}$, as shown in Supplementary Material).

It can be concluded from these SEM measurements that the temperature measured on top of the phosphorous coating surface should be the same as that of the smart coating surface. On the other hand, the temperature measurement cannot be performed in all conditions since the signal intensity emitted by the small amount of phosphorous coating is too low. In our engine case, this limitation shows up when the piston is moving too far from the light source that is why in the following section results will only be shown around top dead center (360 CAD) between 270 CAD after 450 CAD.

\section{Results}

\subsection{Temperature swing measurements - optical SCE}

In order to validate the setup, three measurements have been performed before using the coated pistons. As a first 


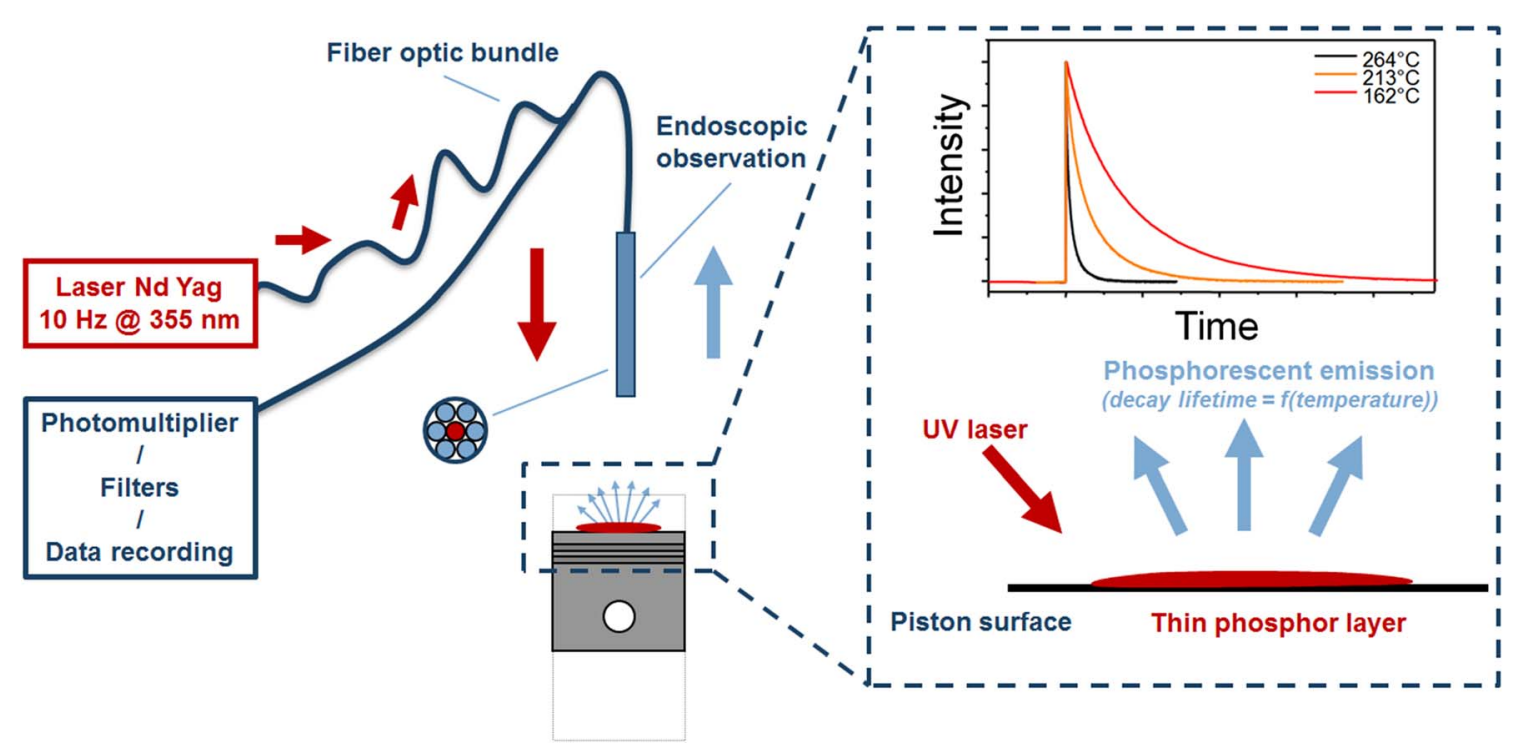

Fig. 1. LIP setup for surface temperature measurement.
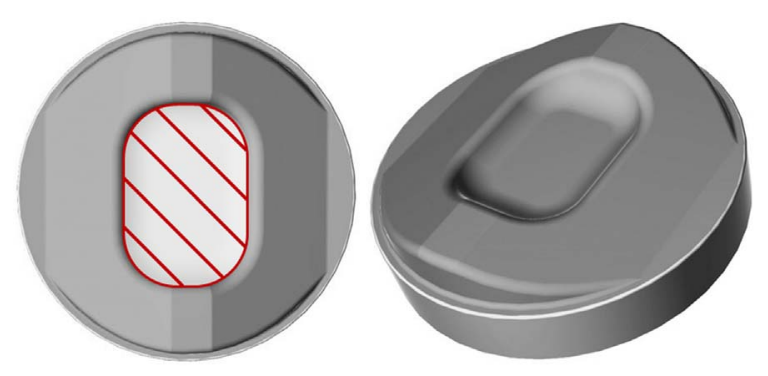

Fig. 2. Phosphorous coating location.

step, the piston surface temperature was measured at a standstill position in warm conditions (no rotational speed, $T_{\text {oil }}=90^{\circ} \mathrm{C}, T_{\text {coolant }}=90^{\circ} \mathrm{C}$ ) and by positioning the piston at TDC and then for the second step the piston surface temperature was measured in warm motored conditions at $1500 \mathrm{rpm}\left(T_{\text {oil }}=90^{\circ} \mathrm{C}, T_{\text {coolant }}=90^{\circ} \mathrm{C}\right)$. It can be noted that a $\mathrm{ZnO}$ phosphorous coating was used for both tests because of its higher sensitivity in the low temperature range than the Lanthanum based phosphorous coating. In standstill conditions, the measured temperature was $90{ }^{\circ} \mathrm{C}$ (i.e., exactly the same as oil and coolant temperatures) and the average standard deviation at each crank angle was around $0.8^{\circ} \mathrm{C}$. In motored conditions the surface temperature was measured between $100{ }^{\circ} \mathrm{C}$ and $107{ }^{\circ} \mathrm{C}$ during the engine cycle which is consistent with the overall expected engine structure temperature. In these conditions, the maximal standard deviation was around $3{ }^{\circ} \mathrm{C}$ (see Fig. 4). Finally, the piston surface temperature was measured during combustion considering two different operating conditions. The maximal standard deviation around top dead center in firing conditions was around $3.5{ }^{\circ} \mathrm{C}$ as shown in Figure 4 (error bars displayed in Fig. 4 stand for twice the standard deviation). Temperature variations shown in Figure 4 close to 270 and 450 CAD are due to the increased distance between the light source and the piston and are therefore not relevant because of the very low phosphorous thickness.

As shown in Figure 5, the measured temperature swing during combustion is around $20{ }^{\circ} \mathrm{C}$ for the uncoated aluminum piston. This temperature variation is in the high range of those available in literature but very similar values have been reported for example by Köpple et al. [17]. The slight angular shift in maximal temperature that can be observed between the two operating points is due to different combustion timings. These results also show that the base temperature before combustion is already very high compared to what could be expected for such operating points in usual engines (surface temperatures in the range of $200-250{ }^{\circ} \mathrm{C}$ are usually reported for full load operating points [18]). This very high base temperature can be explained by the specific architecture of the optical engine, and especially by the absence of oil cooling on the lower part of the piston (neither oil projection nor oil jets).

Measurements have then been performed for coatings $\# \mathrm{~A}, \# \mathrm{C}$, \#D, and \#E. Table 4 summarizes the temperature swings measured for all the tested configurations. Temperature ranges are mentioned in each case and not only single values because of the measurement repeatability. Coatings $\# \mathrm{C}$ and $\# \mathrm{D}$ lead to higher temperature swings than coating $\# \mathrm{~A}$, but the best performance is obtained with coating \#E with temperature swings greater than $100^{\circ} \mathrm{C}$.

Values summarized in Table 4 and shown in Figures 6 and 7 highlight the main effect of smart coatings with temperature swings 2-5 times greater than those measured without coating. These temperature increases do not seem to be directly correlated to the coatings thermal properties (thermal conductivity and heat capacity). Additional investigations are required but it can be assumed that the open porosity and surface roughness might affect the temperature measurements for coatings $\# \mathrm{~A}$ and $\# \mathrm{C}$ which do not have any top sealing layer and which have 

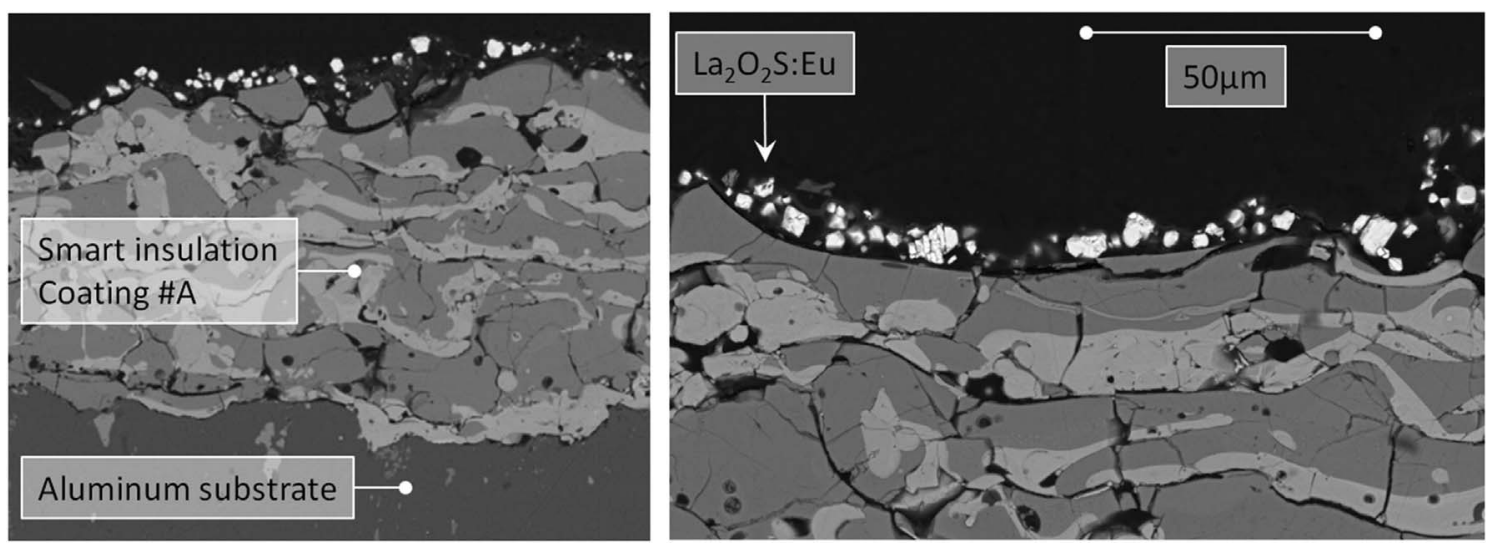

Fig. 3. SEM analyses of phosphorous coating applied on top of smart insulation coating \#A.

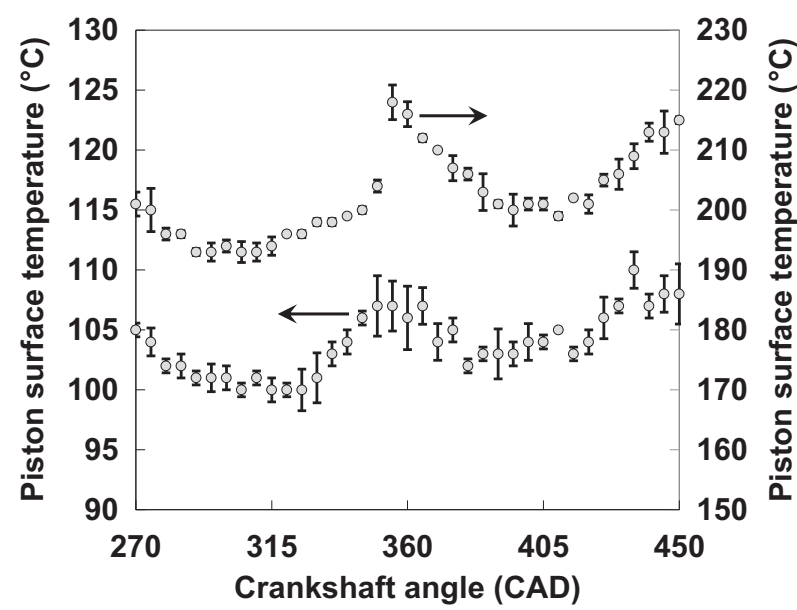

Fig. 4. Piston surface temperatures for uncoated aluminum pistons in motored conditions at $1500 \mathrm{rpm}$ (left axis) and at $2000 \mathrm{rpm}, 4$ bar IMEP $(\lambda=1.21$, right axis).

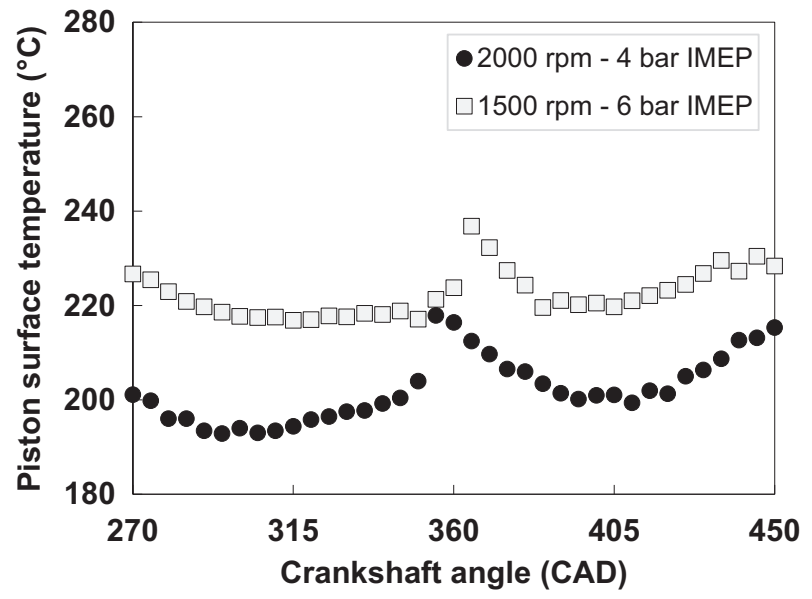

Fig. 5. Piston surface temperature for uncoated aluminum pistons $(\lambda=1.21$ for both operating points).
Table 4. Temperature swing overview.

\begin{tabular}{lcc}
\hline & $2000 \mathrm{rpm}-$ & $1500 \mathrm{rpm}-$ \\
& 4 bar IMEP & 6 bar IMEP \\
\hline $\begin{array}{l}\text { Reference: uncoated piston } \\
\text { aluminium }\end{array}$ & $20-30{ }^{\circ} \mathrm{C}$ & $15-20{ }^{\circ} \mathrm{C}$ \\
Reference + coating \#A & $40-55{ }^{\circ} \mathrm{C}$ & $50{ }^{\circ} \mathrm{C}$ \\
Reference + coating \#C & $55-65{ }^{\circ} \mathrm{C}$ & $\mathrm{NA}$ \\
Reference + coating \#D & $60-65{ }^{\circ} \mathrm{C}$ & $50-60{ }^{\circ} \mathrm{C}$ \\
Reference + coating \#E & $100-120^{\circ} \mathrm{C}$ & $105-110^{\circ} \mathrm{C}$ \\
\hline
\end{tabular}

NA, not available.

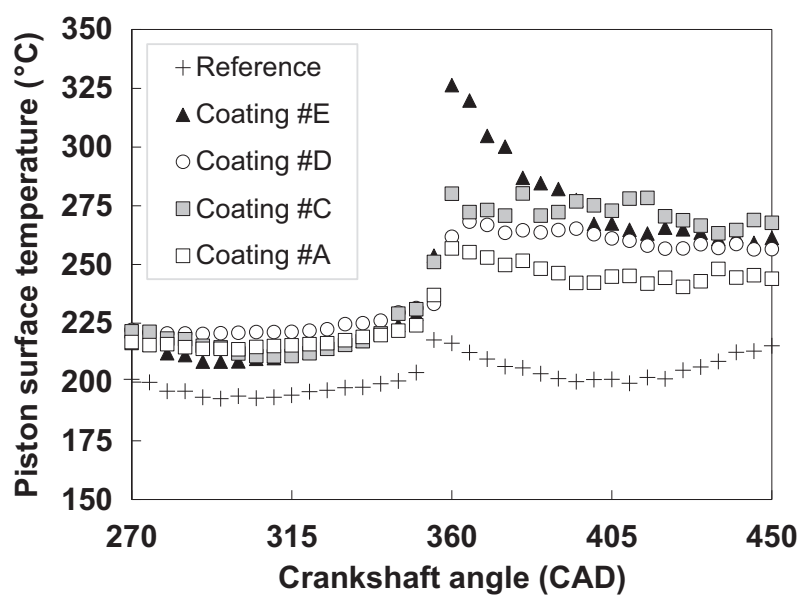

Fig. 6. Piston surface temperatures at $2000 \mathrm{rpm}, 4$ bar IMEP $(\lambda=1.21$ for all configurations $)$.

roughnesses $R_{a}$ higher than the targeted phosphorous coating thickness.

From the coating properties, two groups of coatings can be assumed with different heat transfer physical phenomena. For coatings $\# \mathrm{~A}$ and $\mathrm{ZC}$ with higher roughnesses 


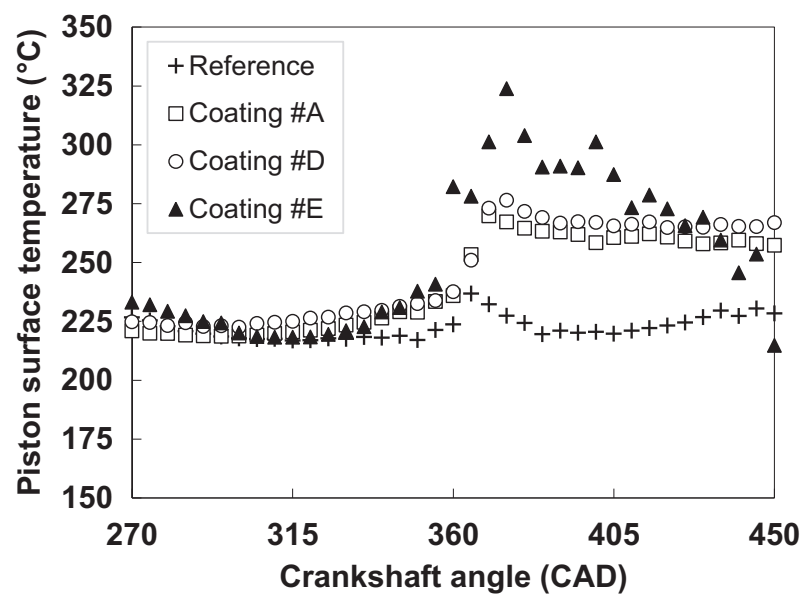

Fig. 7. Piston surface temperatures at $1500 \mathrm{rpm}, 6$ bar IMEP $(\lambda=1.21$ for all configurations).

and open porosity, the accessible heat exchange surface is higher, and the hot gas can penetrate inside the coating and then generates an internal heat exchange. For coatings $\# \mathrm{D}$ and $\# \mathrm{E}$, the heat exchange from gas to solid is conducted only on the surface.

Since all the tested coatings have quite similar thicknesses, it can be assumed that the better performance of coating $\# \mathrm{E}$ compared to coating $\# \mathrm{D}$ is related to the nature of the selected materials and to the stacking of its different layers.

In fact, the layer stacking seems to add contact thermal resistance which reduces the heat flux in addition to the low conductivity materials. Here, the coating \#E shows higher temperature than coating $\# \mathrm{D}$, despite the fact that the heat capacity and heat conductivity are higher. This difference can be explained by higher thermal resistance between coating layers. The coating \# E has one more layer than coating $\# \mathrm{D}$. In addition, the contact thermal resistance of the interface between coating layer can be different depending on the coating layer natures.

In addition to the temperature swings, these measurements show that the coatings do not have a significant negative impact on the piston temperature obtained at the end of compression stroke just before combustion. In other words, these coatings should not have any negative impact on the piston surface temperature during the intake stroke and on the volumetric efficiency. Higher surface temperatures are shown for coating \#E in Figure 7 during early compression stroke (from $270 \mathrm{CAD}$ up to around $300 \mathrm{CAD})$. This measurement complies with a maximal repeatability threshold that was defined to take into account the signal loss when the piston is moving away from TDC, i.e. the measurement is considered as valid. However, with a lower threshold, these measurements close to 270 CAD might not have been validated and results would have been shown in a smaller angular range around TDC. It is confirmed yet that this increased temperature level for coating $\# \mathrm{E}$ is not resulting from the temperature trend during the expansion stroke since temperature measurements performed around TDC at the end of the exhaust stroke show that the piston surface temperature is already stabilized at around $225{ }^{\circ} \mathrm{C}$ (as shown in Supplementary Material). It will also be shown in Section 4.2 that this coating \# $\mathrm{E}$ has no negative impact on volumetric efficiency, meaning that the surface temperature should not be increased during intake stroke.

Thanks to LIP, the performance of various coatings could be quantified in terms of temperature swing. The highest temperature increase during combustion has been measured at around $100-120{ }^{\circ} \mathrm{C}$ with coating \#E. A higher temperature swing of around $140{ }^{\circ} \mathrm{C}$ has been measured by Toyota for the SiRPA coating with a very similar measurement procedure [15]. However, it is important to note that these measurements have been performed for a Diesel engine, for different operating conditions, for different location (on the squish area and not at the center of the piston), and also that temperature swing measured for the uncoated piston was around $45{ }^{\circ} \mathrm{C}$, i.e. around twice as much as that reported here. The temperature swing ratio between coated and uncoated configurations has thus the same order of magnitude.

Regarding the maximal temperature swing phasing, an increase in the phase shift between the peak surface temperature and the peak heat release rate was expected when moving from coating $\# \mathrm{D}$ to coating $\# \mathrm{E}$ due to its higher heat capacity and higher thermal conductivity. This shift increase was not measured and it is assumed that the impact of coating \# $\mathrm{E}$ on the combustion heat release rate compensates the material impact (see Sect. 4.2, Fig. 14).

Based upon these results, it can be expected that the developed smart insulation coatings should have a positive impact on fuel consumption reduction by reducing the temperature difference between the gas and the walls, and thus by reducing the convective heat transfer. It should also be noted that the overall coating performance does not only depend on the maximal temperature reached during combustion, but also on the temperature decay during expansion.

\subsection{Thermodynamic performance - metal SCE}

As mentioned in Section 2, coatings $\# \mathrm{~A}, \# \mathrm{~B}, \# \mathrm{C}$, and $\# \mathrm{E}$ have been tested with the metal SCE. Coatings \#A, \#B, $\# \mathrm{C}$ have been applied on three pistons, and coating \# $\mathrm{E}$ has been applied on piston and cylinder head.

Coatings \# A and \# C applied on the piston surface were the first to be tested and measurements have quickly showed that unburned hydrocarbon emissions were significantly increased by up to $25 \%$ depending on the operating point (see Fig. 8 at 3000 rpm, 7 bar IMEP). Repeatability measurements have been performed for the uncoated reference configuration and for all operating points and confirmed that this increase is higher than the average deviations that can be expected.

Such an increase in unburned hydrocarbon emissions downgrade the engine efficiency and can completely offset the positive effect expected with the insulation coating regarding the reduction of cooling losses. At $3000 \mathrm{rpm}$, 7 bar IMEP, and $\lambda=1.5$, the average specific fuel consumption is around $200 \mathrm{~g} / \mathrm{kW} \mathrm{h}$. An increase in unburned hydrocarbon emissions by around $1 \mathrm{~g} / \mathrm{kW} \mathrm{h}$ as shown in 
Figure 8 is thus equivalent to an increase in fuel consumption by $0.5 \%$ which is in the same order of magnitude as the fuel consumption reduction expected with a smart insulation coating. For that reason, a specific test plan has been defined in order to identify the coatings characteristics explaining this increase in unburned hydrocarbon emissions.

It was first considered that the increase in unburned hydrocarbon emissions might be related to the surface roughness of insulation coatings \#A and $\# \mathrm{C}$. Previous simulation results have shown that the coating surface roughness only has a very limited impact on heat transfer as long as this roughness is kept below $14 \mu \mathrm{m}$ [19] but the potential impact on air-fuel mixture adsorption and desorption mechanisms and on $\mathrm{uHC}$ emissions was not investigated. A rough uncoated aluminum piston has then been produced by sand blasting to reach a similar $R_{a}$ as for coatings \# A and \# $\mathrm{C}$ (around $9 \mu \mathrm{m}$ ). Test results obtained with this rough aluminum piston clearly showed that the surface roughness does not explain the increase in emissions as shown in Figure 8.

It was then decided to investigate the impacts of the open porosities on top of the coating surface. To do so, a double layer coating \#B was produced by sealing the upper part of coating \#A. Thanks to this coating, unburned hydrocarbon emissions could be lowered down to the reference values measured with the uncoated reference piston as shown in Figure 8. Similar measurements have been performed for the other operating points and the same observations were made. In parallel, a similar result was obtained with the optical engine running with port fuel with port fuel injection with coating $\# \mathrm{D}$, meaning that the key driver for the increase in $\mathrm{uHC}$ emissions is the open porosity and not the injection mode. It can also be noted that smoke emissions measured with coatings \# A and \#C are also higher than for the reference, but those measured with coating $\# \mathrm{~B}$ are similar to those of the uncoated reference.

The specifications of coating \# $\mathrm{E}$ have then been defined based upon the results obtained with the previous coatings by combining the optimal materials and by using a sealing layer on top of the coating to close the open porosities. The surface roughness was also minimized according to the available information in the literature $[4,8,11]$. This coating was applied first only on the piston surface just like for the previous coatings. Test results have then shown similar or even lower unburned hydrocarbon emissions than for the reference uncoated configuration but no increase in engine efficiency could be measured. Therefore, this coating has been applied in a second step on both the piston and the cylinder head surfaces (except the valves) to maximize its impact.

Only results obtained at $3000 \mathrm{rpm}, 7$ bar IMEP are illustrated in this article but similar results have been obtained for other operating points. The comparison between the uncoated reference and the coated configuration is thus performed at low load with optimal combustion timing (knock free operation). As for the previous tests, the $\lambda$ variation was repeated twice. Figure 9 shows first the combustion efficiency calculated for this operating point and especially the two test results (1) and (2) with coated parts.

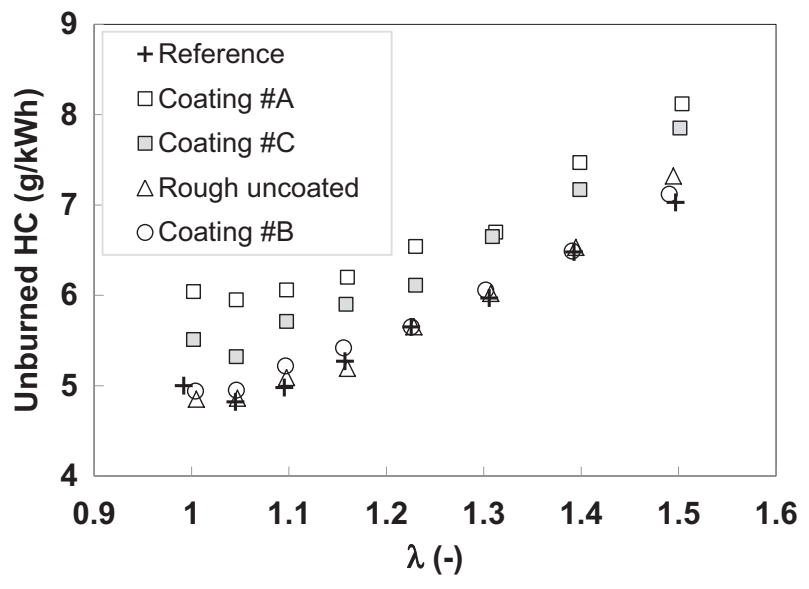

Fig. 8. Unburned hydrocarbon emissions at $3000 \mathrm{rpm}$, 7 bar IMEP.

This efficiency equals $100 \%$ only when the fuel chemical energy is fully converted into heat during combustion, and it can be calculated mainly based upon unburned hydrocarbon and carbon monoxide emissions measured at the exhaust (the full fuel oxidation would only lead to $\mathrm{CO}_{2}$ formation). These results show that combustion efficiency is even slightly better for the coated configurations than for the uncoated reference, confirming thus that the unburned hydrocarbon emissions were well controlled with the optimized coating \#E. Smoke emissions measured for the same configurations are shown in Figure 10. No significant impact of coated parts can be observed regarding smoke emissions but further investigations should be performed by using particles counting systems.

The smart insulation coating aims at reducing the heat transfer between the gas and the walls during combustion, but also during the intake stroke in order to limit the intake air heating which would downgrade the volumetric efficiency. Figures 11 and 12 show that this objective can be achieved with coating \#E since the same intake pressure was required to reach the same load with uncoated and coated configurations (intake temperature is kept constant at $40{ }^{\circ} \mathrm{C}$ for all operating point and all engine configurations). A slightly higher volumetric efficiency is even obtained close to the stoichiometry and no negative impact is observed in lean conditions.

However, as shown in Figure 13, the indicated efficiency defined as the ratio between the indicated work and fuel input energy is not higher for the coated configurations. In the best case scenario, only the same efficiency as for the reference configuration can be reached. The expected maximal benefit in indicated efficiency with insulation coatings is moderate, especially if only the piston surface is coated, and typically around $0.5 \%$ abs. $[7,11]$. However, Figure 13 shows that the indicated efficiencies achieved with coated configurations are overall slightly lower than that of the uncoated reference and the same observation has been made for other operating points: taking into account the fuel consumption measurement accuracy, coatings have either a negative or a neutral impact on efficiency. 


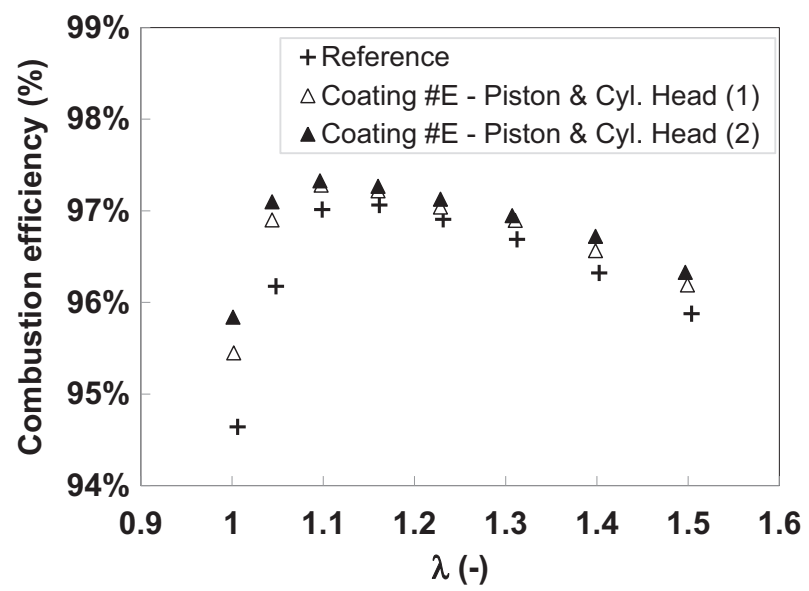

Fig. 9. Combustion efficiency at $3000 \mathrm{rpm}, 7$ bar IMEP.

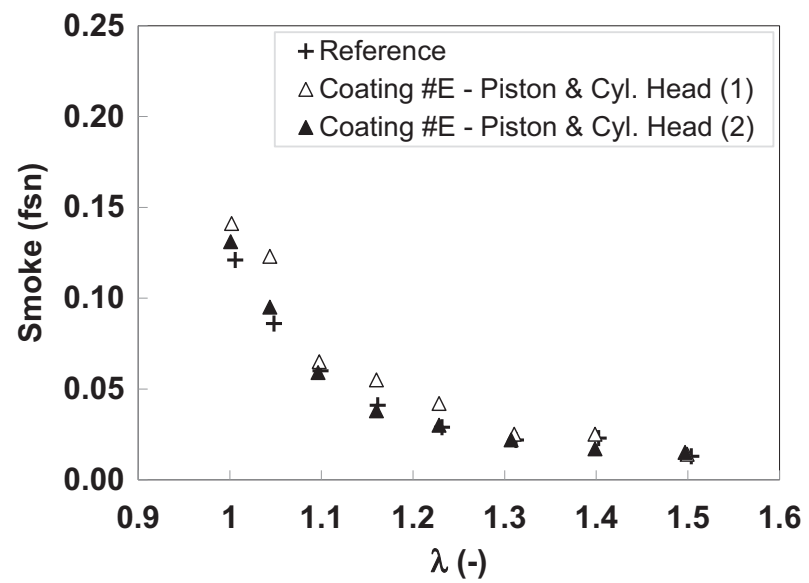

Fig. 10. Smoke emissions at $3000 \mathrm{rpm}, 7$ bar IMEP.

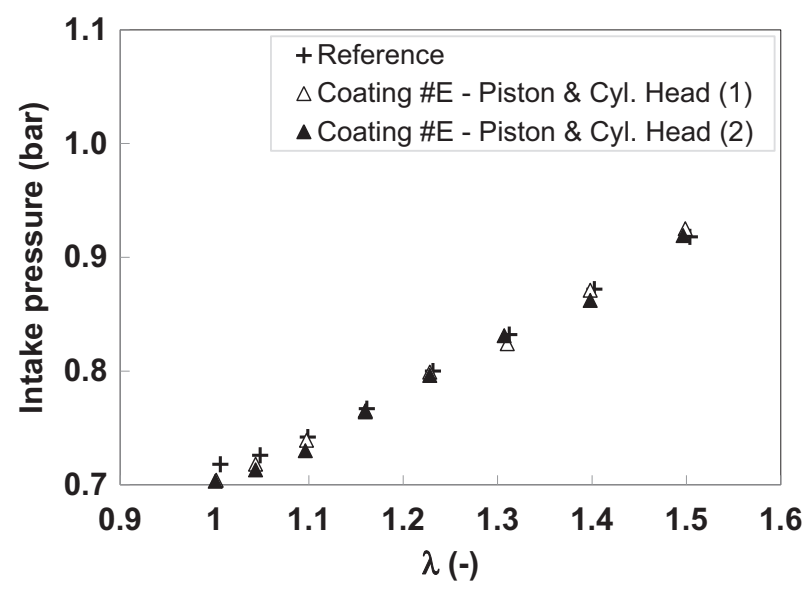

Fig. 11. Intake pressure at $3000 \mathrm{rpm}, 7$ bar IMEP.

The comparisons of indicated efficiencies for coated and uncoated configurations require to quantify the complete heat balances.

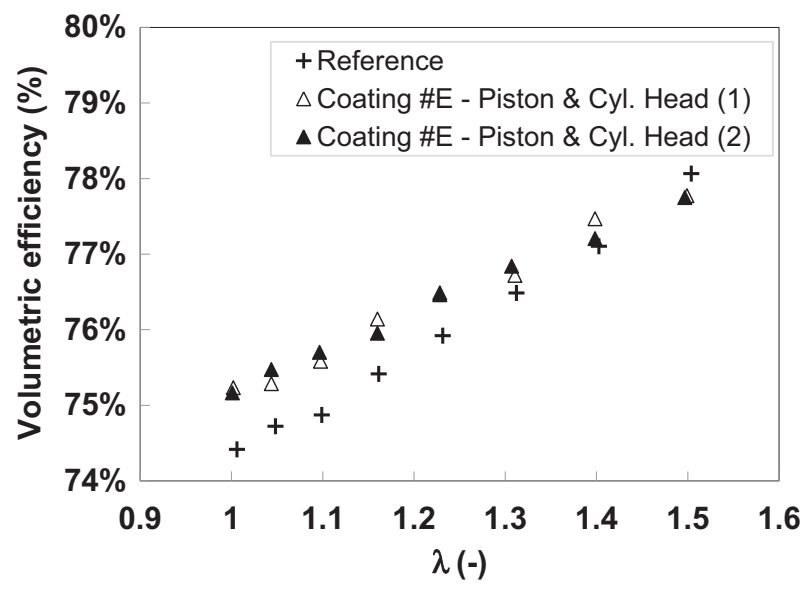

Fig. 12. Volumetric efficiency at $3000 \mathrm{rpm}, 7$ bar IMEP.

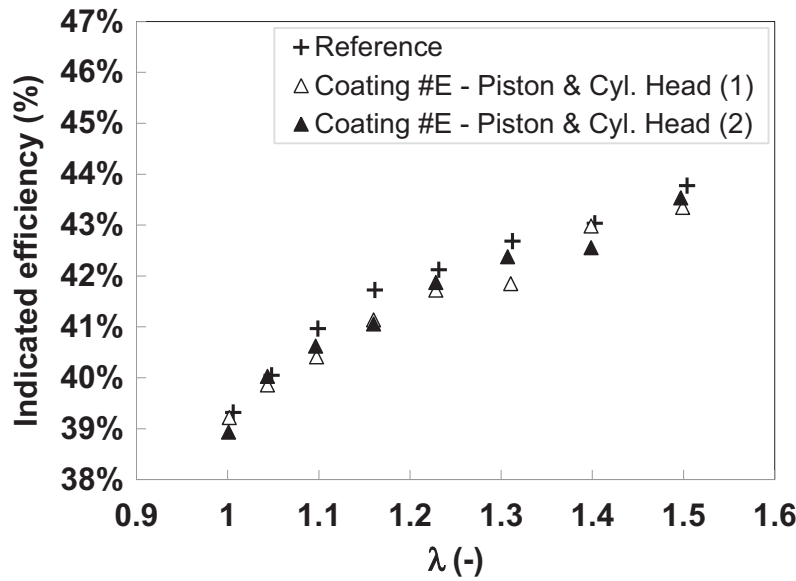

Fig. 13. Indicated efficiency at $3000 \mathrm{rpm}, 7$ bar IMEP.

- From $\lambda=1$ to $\lambda=1.5$, the fuel input energy decreases from 740 down to $660 \mathrm{~J}$ because of the increased efficiency.

- For the same $\lambda$ variation, the average unburned energy is around $22 \mathrm{~J}$ (i.e., around $3 \%$ of the fuel input energy as shown above in Fig. 9) with a minimal value close to $19 \mathrm{~J}$ and a dispersion between the uncoated and coated configurations of around $2 \mathrm{~J}$. The dispersion is thus around $0.3 \%$ of the fuel input energy.

- The same dispersion of around $2 \mathrm{~J}$ is observed between the coated and uncoated configurations in terms of pumping losses which are on average close to $18 \mathrm{~J}$. Here again, the dispersion is thus around $0.3 \%$ of the fuel input energy.

- For a given $\lambda$, the mixture heat capacity is assumed to be the same for coated and uncoated configurations since the air-fuel ratio and dilution ratio with residual burned gases are not affected by the coating, and also because it has been shown that the coating has no impact on volumetric efficiency and mixture temperature at the intake valve closing timing (see Fig. 12). 


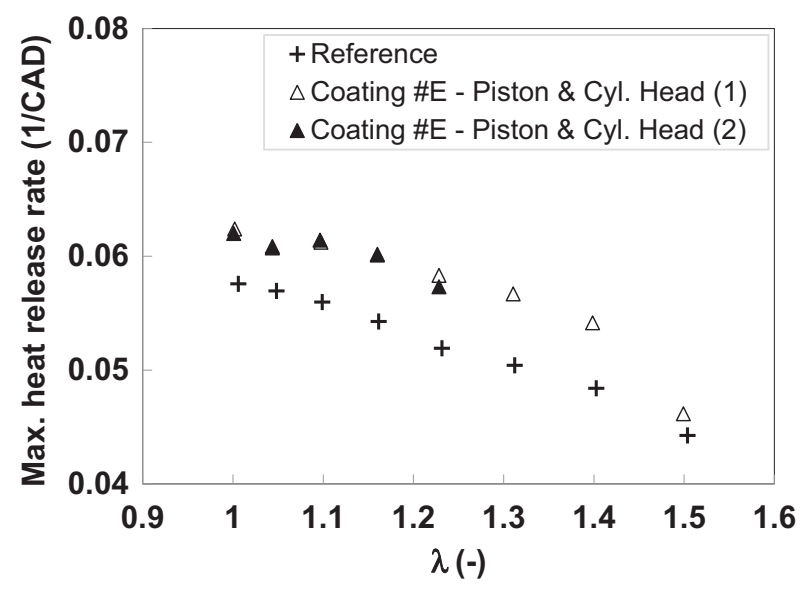

Fig. 14. Maximal heat release rate at $3000 \mathrm{rpm}, 7$ bar IMEP.

- No knock can be observed with this engine at such a low load, which means that the comparison of coated and uncoated configurations is performed at the same optimal combustion timing. However, some distinct effects can be observed on the combustion process. Figure 14 shows that the maximal heat release rate is clearly increased with coating $\# \mathrm{E}$, coherently with the slightly higher NOx emissions as shown in Figure 15. These results indicate that the thermal environment inside the combustion chamber has been modified in such a way that the combustion speed was higher and that the NOx thermal formation process was enhanced. This observation would thus confirm the thermal performance of coating $\# \mathrm{E}$ which led to the maximal temperature swing during the experiments performed in the optical engine (see Sect. 4.1).

Combustion analyses based upon the first law of thermodynamics were then performed to calculate the cooling losses occurring inside the combustion chamber (excluding thus the convective exchanges inside the exhaust ports). Surprisingly, these analyses have shown that the cooling losses with coatings were higher than for the uncoated reference as shown in Figure 16. A maximal difference of around $10 \mathrm{~J}$ can be observed between coated and uncoated configurations, which means around $1.4 \%$ of the fuel input energy. This variation is higher than those of pumping losses and unburned energies, and could explain on its own the decrease in indicated efficiency shown in Figure 13. In parallel, a small decrease in exhaust temperatures is observed for the tests performed with coatings but that decrease would only account for less than $1 \mathrm{~J}$, confirming thus that the increase in cooling losses is directly balanced by a decrease in indicated work. This unexpected observation was confirmed for all the operating points.

To summarize, higher unburned hydrocarbon emissions have been measured first with coatings \# A and \#C applied on the piston surface. Additional investigations have then shown that the surface roughness has no impact on these emissions contrary to the open porosity on top of the smart

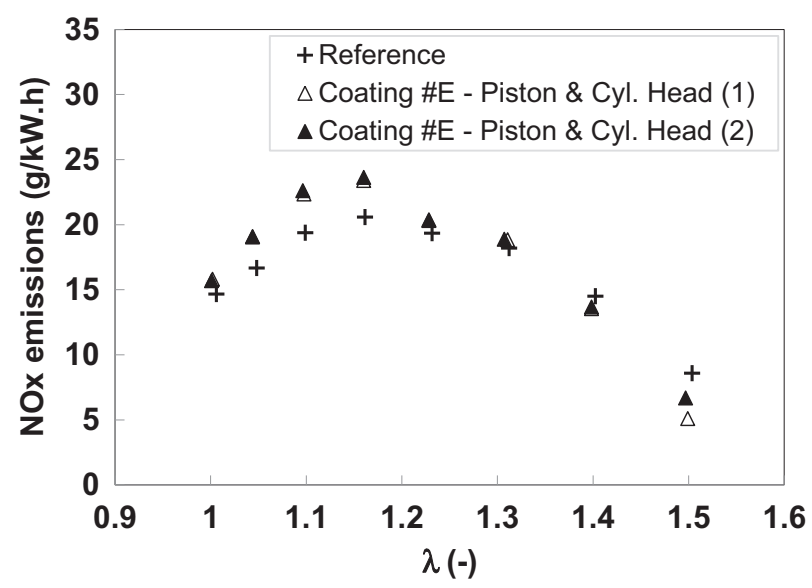

Fig. 15. NOx emissions at $3000 \mathrm{rpm}, 7$ bar IMEP.

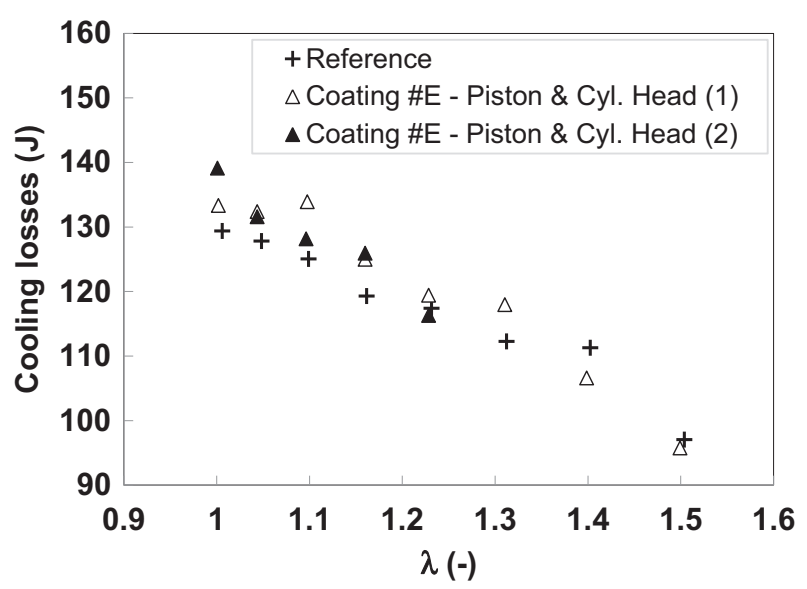

Fig. 16. Cooling losses inside the combustion chamber at 3000 rpm, 7 bar IMEP.

insulation coating. This observation was then confirmed with coating \# $\mathrm{E}$ when applied on the piston surface only, and then on the piston and cylinder head surfaces. With this later configuration, clear effects could be observed compared to the uncoated reference but no fuel consumption reduction could be measured. On the contrary, for most operating points, increases in fuel consumption and in cooling losses were observed. This mixed result suggests that the heat balance is not only affected by the reduction in the temperature difference between the walls and the gas as expected, or at least not as directly as expected. Several additional hypotheses are now considered to explain how the heat transfer in spark-ignition engines can be modified when insulation coatings are used. As mentioned by Uchida and Osada [4], it could be assumed for example that the surface temperature increase or the coating surface texture could lower the thermal boundary layer thickness and induce an increase in the heat transfer coefficient that would counterbalance the positive effect of the decreased temperature difference between the gas and the walls. Kosaka et al. [20] have also recently reported some interest- 
ing investigations on this topic. In these works, LIP and coherent anti-Stokes Raman spectroscopy are used to measure the wall and gas phase temperatures with a side wall quenching burner configuration, without any insulation coating but with a variable wall temperature. It is shown that a high wall temperature promotes the decrease in the quenching distance and the increase in gas phase temperature near the wall. Consequently, the laminar flame speed close to the wall is also increased, the flame can propagate closer to the wall and the resulting heat flux is increased despite the higher wall temperature. This counterintuitive mechanism could also explain the mixed results obtained so far with insulation coatings in the study reported here. These observations are essential to guide the future developments since it is shown that the thermal performance (temperature swing) of smart insulation coatings should be analyzed and optimized as a function of the engine operating conditions that could affect the thermal boundary layer thickness such as the fuel used, or the overall ignition and combustion modes (e.g., spark-ignition, compression ignition, or any other mix combustion mode such as spark-assisted compression ignition).

\section{Conclusion}

Five different smart insulation coatings featuring low thermal conductivity and heat capacity were applied on aluminum engine parts with the atmospheric plasma spray technique and were tested with two different engines. Results have shown that the piston surface roughness has no impact on unburned hydrocarbon emissions, but the open porosities on top of the smart insulation coating layer must be sealed in order to avoid significant increases in unburned hydrocarbon emissions. Thanks to the LIP technique, a maximal temperature swing of more than $100{ }^{\circ} \mathrm{C}$ has been measured at low load with the optimized coating $\# \mathrm{E}$, confirming thus the expected impact of the low thermal conductivity and heat capacity, and suggesting thus a positive impact on fuel consumption. Even if some positive distinct impacts have been observed when this optimized coating \#E was applied on both piston and cylinder head surfaces of the metal SCE, cooling losses inside the combustion chamber were increased. As a result, it was observed that the resulting specific fuel consumption was increased, or in the best case scenario kept constant taking into account the measurement accuracy.

Several perspectives are now possible to deepen the analysis and to further improve these results. Regarding the fundamental effects of coatings, additional experimental or numerical investigations could be performed to evaluate the effects of the temperature swing distribution on the whole piston and cylinder head surfaces. The impacts of coating on the thermal boundary layer should also be investigated in relation with the considered combustion mode since some effects might be different between diffusion and propagation flames. Alternative combustion systems should also be considered to identify the best match between the expected insulation effects and the combustion strategy. Finally, further coatings optimizations are also required to maximize the impacts of fuel consumption but in that respect a fine trade-off will have to be found between the increased porosity and the mechanical resistance.

\section{Supplementary materials}

Supplementary material is available at https://ogst. ifpenergiesnouvelles.fr/10.2516/ogst/2020006/olm

Figure 1S. Chemical composition analysis of phosphorous coating crystals by Energy Dispersive X-ray Spectroscopy. Figure 2S. Piston surface temperatures at $2000 \mathrm{rpm}, 4 \mathrm{bar}$ IMEP $(\lambda=1.21)$ at the end of exhaust stroke (from -60 to $0 \mathrm{CAD}$ ) and beginning of intake stroke (from 0 to $60 \mathrm{CAD})$.

Acknowledgments. This project has received funding from the European Union's Horizon 2020 research and innovation programme under grant agreement No. 724084. The authors would like to thank F. Moreau, T. Colliou and N. Leblanc for the engine tests and for the SEM analyses.

\section{References}

1 Bryzik W., Kamo R. (1983) TACOM/Cummins Adiabatic Engine Program, SAE Technical Paper 830314. doi: 10.4271/ 830314.

2 Assanis D., Mathur T. (1990) The effect of thin ceramic coatings on spark-ignition engine performance, SAE Technical Paper 900903. doi: 10.4271/900903.

3 Binder C., Abou Nada F., Richter M., Cronhjort A., Norling D. (2017) Heat loss analysis of a steel piston and a YSZ coated piston in a heavy-duty diesel engine using phosphor thermometry measurements, SAE Int. J. Engines 10, 4, 1954-1968. doi: 10.4271/2017-01-1046.

4 Uchida N. and Osada H. (2017) A new piston insulation concept for heavy-duty diesel engines to reduce heat loss from the wall. SAE Int. J. Engines 10, 5, 2565-2574. doi: 10.4271/2017-24-0161.

5 Uchihara K., Ishii M., Nakajima H., Wakisaka Y. (2018) A study on reducing cooling loss in a partially insulated piston for diesel engine, SAE Technical Paper 2018-01-1276. doi: 10.4271/2018-01-1276.

6 Fujimoto H., Yamamoto H., Fujimoto M., Yamashita H. (2011) A Study on Improvement of Indicated Thermal Efficiency of ICE Using High Compression Ratio and Reduction of Cooling Loss, SAE Technical Paper 2011-011872. doi: 10.4271/2011-01-1872.

7 Caputo S., Millo F., Cifali G., Pesce F. (2017) Numerical investigation on the effects of different thermal insulation strategies for a passenger car diesel engine, SAE Int. J. Engines 10, 4, 2154-2165. doi: 10.4271/2017-24-0021.

8 Kaudewitz T., Lange F., Rablbauer R., Mork A., Schüttenhelm M., Frambourg M., Lösche-ter Horst T., Pitsch H. (2018) Innovative piston technologies for future efficiency and emission targets, in: 27th Aachen Colloquium Automobile and Engine Technology, October 8-10, 2018, Aachen, Germany.

9 THESTA (2016) Innovatives Thermomanagement für Stahlkolben, Final Report. doi: 10.2314/GBV:870173170. 
10 Schaedler T., Andruskiewicz P. (2018) Temperature-following thermal barrier coatings for high-efficiency engines, DOE Vehicle Technologies Annual Merit Review.

11 Toyota Central R\&D Labs., Inc. (2017) Challenges of internal combustion engines for achieving low-carbon society (full special issue), RED Review of Toyota $C R D L 48,4$. https://www.tytlabs.com/review/, ISSN 2186-9014.

12 Yamashita H., Kawaguchi A., Iguma H., Tanaka K., Ogawa T., Yamashita C., Fukui K., Wakisaka Y. (2018) Heat insulation by temperature swing in combustion chamber walls (fifth report), JSAE 20184159 (in Japanese).

13 Bouteiller B., Allimant A., Zaccardi J.-M., Chérel J. (2019) New ceramic thermal barrier coatings development in a spark-ignition engine - experimental investigation, in: International Thermal Spray Conference and Exposition, May 26-29, 2019, Yokohama, Japan.

14 Kashdan J., Bruneaux G. (2011) Laser-induced phosphorescence measurements of combustion chamber surface temperature on a single-cylinder diesel engine, SAE Technical Paper 2011-01-2049. doi: 10.4271/2011-01-2049.

15 Fukui K., Wakisaka Y., Nishikawa K., Hattori Y., Kosaka H., Kawaguchi A. (2016) Development of instantaneous temperature measurement technique for combustion chamber surface and verification of temperature swing, SAE Technical Paper 2016-01-0675. doi: 10.4271/2016-01-0675.
16 Knappe C., Andersson P., Algotsson M., Richter M., Linden J., Alden M., Tuner M., Johansson B. (2011) Laser-induced phosphorescence and the impact of phosphor coating thickness on crank-angle resolved cylinder wall temperatures, SAE Technical Paper 2011-01-1292. doi: 10.4271/2011-01-1292.

17 Köpple F., Seboldt D., Jochmann P., Hettinger A., Kufferath A., Bargende M. (2014) Experimental investigation of fuel impingement and spray-cooling on the piston of a GDI engine via instantaneous surface temperature measurements, SAE Technical Paper 2014-01-1447. doi: 10.4271/2014-01-1447.

18 Ishibashi A., Nakamura M., Muramatsu H. (2014) Piston temperature measurement in internal combustion with telemetric method, SAE Technical Paper 2014-32-0051. doi: 10.4271/2014-32-0051.

19 Broatch A., Olmeda P., Margot X., Gomez-Soriano J. (2019) Numerical simulations for evaluating the impact of advanced insulation coatings on $\mathrm{H}_{2}$ additivated gasoline lean combustion in a turbocharged spark-ignited engine, Appl. Therm. Eng. 148, 674-683. doi: 10.1016/j.applthermaleng.2018.11.106.

20 Kosaka H., Zentgraf F., Scholtissek A., Bischoff L., Häber T., Suntz R., Albert B., Hasse C., Dreizler A. (2018) Wall heat fluxes and $\mathrm{CO}$ formation/oxidation during laminar and turbulent side-wall quenching of methane and DME flames, Int. J. Heat Fluid Flow 70, 181-192. doi: 10.1016/j. ijheatfluidflow.2018.01.009. 